\title{
Malaysian early career researchers on the ethics of scholarly publishing
}

\author{
A. Abrizah ${ }^{1,2}$, Nordiana Ahmad Kharman Shah ${ }^{1}$ and David Nicholas ${ }^{2}$ \\ ${ }^{1}$ Department of Library \& Information Science, \\ Faculty of Computer Science \& Information Technology, \\ University of Malaya, Kuala Lumpur, MALAYSIA \\ ${ }^{2} \mathrm{CIBER}$ Research Ltd. \\ 1 Westwood Farmhouse, Greenham, Newbury, UK \\ e-mail: abrizah@um.edu.my; dina@um.edu.my (corresponding author); \\ Dave.Nicholas@ciber-research.eu
}

\begin{abstract}
Publication ethics are rarely taught. This paper presents research into the knowledge of scholarly publishing ethics among Malaysian early-career researchers (ECRs). This research comes from year two of a projected three-year-long study of ECRs from seven countries (China, France, Malaysia, Poland, Spain, the UK, and the US), for which semi-structured in-depth interviews were conducted with study participants. For the findings reported in this paper, 12 ECRs from science and social science disciplines at five Malaysian research-intensive universities were interviewed during the period from February to June 2017. The interview record was compared with the previous year's (2016) record to identify changes in interviewees' responses to a set of questions on their knowledge of ethics in scholarly communication. In addition, contextual data were obtained from the CVs of the ECRs. Our findings indicate that the attitudes and behaviours of Malaysian ECRs in relation to scholarly communication ethics have changed in the passage of one year. We observed noteworthy changes in ECRs' knowledge of unethical behaviours. As compared with data from 2016, the ECRs are more verbose in their responses on what is generally regarded as ethical and unethical in research and/or publishing practices. Authorship policies, the academic evaluation system, and the scrutiny which will keep the lid on any unethical behaviours are the most important factors bringing about the changes we observed. This paper suggests that ECRs' manifestation of publishing ethics is gauged through their publishing practices.
\end{abstract}

Keywords: Publication ethics; Scholarly publishing; Scholarly communication; Authorship policy; Research integrity.

\section{INTRODUCTION}

The pressure to publish may lead to "ethical lapses" (Schroter et al. 2018) among early career researchers (ECRs). ECRs are thought to be "particularly at risk of committing scientific misconduct" (Fanelli, Costas and Larivière 2015) particularly because they may not have fully understand the principles and ethics in science communication (Anderson et al. 2007). They also have not established a professional reputation, and therefore they may face all or nothing risk situation from attempting scientific misconduct (Lacetera and Zirulia 2011). ECRs are of great interest not just because they are the new wave, but they are also the biggest wave (Nicholas et al. 2017c) - they are by far the largest group in academia so they have the power to make changes. Therefore, they merit long, detailed and continuous investigation. For ECRs in the sciences, in particular, publication record is the fundamental metric in the academic promotion system (Walker et al. 2010). Since researchers are 
primarily funded by the public, they are accountable to publish ethically (Edwards and Roy 2017; Tennant et al. 2016) and are also responsible for creating a culture that values ethical practices to increase scientific rigor, transparency and reproducibility.

Such concerns led to an international investigation of the behaviours and perceptions of more than 100 researchers using in-depth interviews, involving the USA, UK, France, Poland, Spain, China and Malaysia. This paper illustrates Malaysia's side of the report, which is a part of the larger international study that concentrated on the attitudes and practices of ECRs in scholarly communication (Nicholas et al., 2017a; 2017b; 2017c; Rodríguez-Bravo et al., 2017). In the context of Malaysia, ECRs are researchers between 30-39 years old, who are not more than ten years from receiving their doctorates operating without tenure. They represent the future of research in Malaysia and their attitudes and behaviour matter. Malaysian ECRs, especially in research-intensive universities, are regarded as a major driving force of scientific research by their institutions. This gives them a lot of opportunities and supportive conditions to do good research, but it also places tremendous pressure on them (Friesenhahn and Beaudry 2014; Kıraç 2016). Similar to their senior counterparts, ECRs are driven by evaluation policies that determine where and how they publish.

The paper is built on a three-year longitudinal study on ECRs and their experiences in publishing. The first year of the study provided a benchmark of behaviours and attitudes against which change could be measured - specifically their attitudes to peer review, publication behaviour and collaboration, knowledge sharing, open access, social media and emerging impact mechanisms (Abrizah 2016). The second year actually follows through the first year when anything reasonably solid about change and trends can be determined. Therefore, the second-year report concentrates on the changes in the ECRs scholarly communication attitudes and behaviours (Abrizah 2017). A greater understanding on issues previously reported was obtained because of the prolonged engagement with the ECRs and the fact that ECRs became more open due to their familiarity and exposure with the topic as provided in the paper. The value of returning to ECRs meant that new questions could be asked as suggested by researchers from the collaborating countries and the Publishing Research Consortium, which commissioned the international study.

Now, at the end of the second year of the study, which involved interviewing the ECRs, we have sufficiently robust data to share on the assessment of ECRs' knowledge on publication ethics, in regards to where and how to publish. The main objective is to know where ECRs publish their research and how they integrate their understanding of the publication ethics in the publication process - from journal selection to dissemination or sharing. In particular, this paper focuses on the ethics in publishing: (a) where ECRs publish; and (b) their knowledge of unethical practices. This study is relevant as there have been no studies involving a periphery country context such as Malaysia, aside from non-empirical opinion pieces, relating to this topic at present.

\section{LITERATURE REVIEW}

The integration of research and development is broadly perceived as one of the most important factors in economic and socioeconomic growth in most countries around the world. Research plays an indispensable role in an information-driven economy. ECRs assume a focal part in this new information-driven economy and they are considered as the pool from which future leaders in science will emerge. With their new experience and 
ideas, ECRs are imaginative and enthusiastic researchers who assume a great part in an information-driven economy. Thus, getting an insight into how ECRs can succeed and add to the knowledge pool and the issues they encounter is a focal point of worry for nations around the world (Friesenhahn and Beaudry 2014).

However, on an individual level, the ECRs' life is often described as challenging that render it a difficult, vulnerable, and perilous experience (CIBER Research Ltd. 2016). Fransman (2014) illustrates that ECRs are in a progressive transition, with their scholarly character developing through their varying interest, qualities, resources, and lifestyles. In this manner, there is a need to balance priorities and needs as a new and maturing scientist. They endeavour to build themselves in a perpetually focused scholarly community while attempting to tackle the demand of other aspects of teaching and institutional commitments are evidently of principal significance (Nicholas et al. 2016). One of the ways that academics and ECRs respond to this is to publish in international reputable journals. However, expectation that ECRs must conduct relevant researches and publish them in journals with high-impact factor has become a difficult endeavour in a highly competitive market for grants, jobs, reputation, tenure, promotion and even success trajectory in general (Mitcheson, Collings, and Siebers 2011). The pressure is also rooted from the need of universities and higher education institutions to attain good standing in ranking systems such as the Research Excellence Framework (REF), QS World University Ranking and the Times Higher Education World University Ranking.

In the UK, the goal to obtain 20 percent score for research "impact" in the REF has put pressure to ECRs to publish in high-ranking or high-impact journals, which leads to undesirable outcome on researchers' creativity and choice of where to publish their papers (Nicholas et al. 2013; Nicholas et al., 2017b). Further, the pressure becomes more problematic when ECRs are pushed to commit research misconducts just to obtain the required points for tenure and 'impact.

Kim (2010) argued that there are two categories of research misconduct: research integrity violations and publication ethics violations. Research integrity violations include fabrication, falsification, and plagiarism; while on the other hand, publications ethics violations include duplicate publication and/or self-plagiarism, and inappropriate authorship (Uhm 2016). In this case, publications broadly include scientific journals, abstracts, and proceedings of the meetings, research reports, thesis and dissertations, books, magazines, and even the internet postings. Other publishing violations also include ascribing authorship and misappropriation, writing support; disclosing conflicts of interest; access to data; redundant publication; dual submission; salami publishing; image manipulation (Roberts 2009). Publication ethics violations also include fake data and tendentious interpretations, unclear authorship, and unacceptable submissions (Stoilescu and McDougall 2010). Because of its being wide range and complex, the concept of publication ethics is sparsely presented in various papers, either as reviews or as separate discussion of each publication ethics violation (e.g., Rushby 2017; Brice and Bligh 2004; Denholm 2006; Serebnick and Harter1990; Tandon, Mahajan, Sharma and Gupta 2006; Stoilescu and McDougall 2010). Hence, it is the focus of this paper to bring out the challenges of ECRs relating to publication and publication ethics.

ECRs are enthusiastic about making an enduring effect but they need viable institutional help to extend the effect of their exploration and require the discipline needed to convey impactful research while adhering to research and publication ethics (Marcella et al. 2017). 
Hence, it is seen that ECRs place more emphasis on research impact rather than their experience in their knowledge and adherence to publication ethics per se.

However, Nicholas et al. (2017b) found that ECRs are generally more interested in increasing reputation and productivity as these are considered to be the ways to obtain appointments, promotions, and research funding. In some ways, ECRs respond to the pressure to become published scientists and express their notion to have a lasting and strong effect through publication is to submit articles in open access (OA) journals (Nicholas et al. 2015; Nicholas et al., 2017b; Kieńc 2017), which are also following unethical publication and editorial practices sometimes. It is therefore important to understand how ECRs deal with the challenge of authorship and other ethical considerations in publishing as it may affect their reputation and the positive scholastic consequences of having collaboration and publications.

With the notion that publishing is a time-consuming activity and a force that pressures them towards career promotion and grants (Pontika 2015), there is also a tendency for ECRs to commit publication misconduct. For instance, other researchers, including ECRs, often submit articles in a low-impact journal and then submit a similar paper to another indexed journal (Kıraç, 2016) as a way to respond to the need to have more publications. Fanelli et al. (2015) mentioned that ECRs could be committing scientific misconduct, including publication misconduct, because of a lack of full internalization of the ethos and principles of science, and an insufficient embodiment of professional reputation. Moreover, their insufficient experience in publishing and high risk-taking behaviour also affects why they engage in such negative practice. Nevertheless, even though ECRs are prone to questionable research practices because of such pressures, these are not to be used as an excuse for carelessness or misconduct since it is important for any researcher or scientist to uphold integrity in promoting science (Noyori and Richmond, 2013).

While there have been a lot of studies that looked into the scientific misconducts in various aspects of research and publication processes, most of these focused on the practices of scientists (Martinson, Anderson, and De Vries 2005; LaFollette 2000) or mostly in the medical research field (Kalichman and Friedman 1992; Tijdink, Smulders, Vergouwen, de Vet, and Knol 2014; Kornhaber, McLean, and Baber 2015; Schroter et al. 2018). Very few were conducted to understand the experiences of ECRs and their vulnerability to committing unethical practice of publishing papers in scientific journals. The idea of looking into publication ethics among ECRs is the fact that scientific misconduct is very broad "from honest errors to outright fraud" (Nylenna and Simonsen, 2006), and publication misconduct is in between continuum. Publication ethics according to Nugent (2013) is a set of rules of conduct in publishing results of scientific research or other scholarly work and this may include protection of intellectual property, disallowing re-publication, avoiding plagiarism, and issues on authorship among others.

The aforementioned problems are not uncommon in ECRs especially when they are pressured to publish in journals. This is also often evidenced by the publication of articles in predatory journals, which is a type of vanity publishing that usually ask authors to pay in exorbitant prices in order to publish (Berger 2017). This means then that the more ECRs who are pressured to publish, the more predatory journals with low quality that lure researchers exist. Rushby (2017) claims that this system makes ECRs to becoming misguided to believe that more submissions increases their chances of being published even if the journal is of low quality. The quality of a journal may also be determined by the reliability of published information, which may also be a reflection of scientific misconduct. 
This is however not given too much consideration by ECRs because they are into responding to the pressure of "publish or perish" standards as well as tenure and ranking requirements (Kıraç 2016). Moreover, the need to comply with ethical rules becomes blurred because they feel that academic upgrading is more important than following rules of publication ethics. Such actions result in a tendency to commit publishing ethics misconduct or questionable research practices related to publishing.

The studies mentioned in this review point to the increasing pressure to publish for tenure and to satisfy the research assessment exercise. However, these studies mostly talk about scientific and publishing misconduct in general, with some studies dealing specifically with publication violation matters, such as plagiarism and authorship issues. There is an absence of literature that examines the behaviour and attitude of ECRs in respect to the ethics of publishing or its misconduct, particularly in the Malaysian context. Although there have been some papers that emphasize how publishing misconduct can be avoided, little research has gathered first-hand information about ECRs' knowledge and/or commission of such misconduct.

\section{SITUATIONAL ANALYSIS AND RESEARCH OBJECTIVE}

Scholarly publishing is important in a university career. It is generally expected that the results of research will be published in scholarly journals. However, publishing is not a matter of sending the article to any journal. Since scholarly publications are expected to provide a detailed and permanent record of research, the work must be conducted and reported honestly, objectively, and fairly, and that the target journal be carefully selected (Abrizah 2018). The process of selecting the appropriate journal has become increasingly complex due to the proliferation of journals, areas of specialization, and emergence of interdisciplinary topics. Besides ease, reach and impact, authors also keep reputation of both high quality and publishing excellence at the forefront of their mind when searching for a journal to publish in. The strength of a journal is often directly related to the strength of its ethics. The process of knowing where, how and what to publish can be very helpful for new academics. Publication planning can help authors achieve and maintain high standards of transparency and integrity.

In countries currently on the "periphery of the scholarly endeavor" such as Malaysia (Abrizah et al. 2015), productivity and impact are formally built into promotion criteria, and this may have forced scientists to publish continuously and successfully to maintain their careers. The more science policy focuses on research influence, the more researchers and institutions are confronted with evaluations based on publications and citations. The rising frequency of retractions of Malaysian papers that occurred mainly due to misconduct (Yanti Idaya Aspura, Noorhidawati and Abrizah 2018) may have elicited concern of the scientific community and questioned the integrity of the researchers. Exploring reasons for retractions are important for assessing the extent of publication practices and contributes to understanding of publication ethics and integrity. With the dearth in the literature on Malaysian ECRs' publication practices and misconduct, this paper contributes to the understanding of these experiences and scenario.

The purpose of the paper is to study over time the evolving behaviours and attitudes of ECRs in Malaysia in respect to ethics of scholarly publishing - where they publish their precious research and their knowledge of publication ethics. Within this broad area, the key priority areas include: journal selection; perceptions as regards to Open Access publishing, mega journals, authorship line-up, reproducibility of research, knowledge of unethical publishing, as well as the ethics of sharing. The areas are investigated in this 
paper because these are parts of the publication process that ECRs undergo before they are able to publish their outputs. Hence, it is important to know how ECRs experience such processes as they might commit unethical practices in each of these steps. The study attempts to answer the following research questions: How do early career researchers apply their understanding of the ethics in the scholarly communication process?

\section{METHOD}

Data are based on face-to-face interviews conducted from 1 March to July 2016 (first year), and 1 February through 30 June 2017 (second year). All 12 ECRs purposively sampled participated in all three years were from the five research-intensive universities in Malaysia. The participants had a chance to pre-read the interview schedule (and again revised 2017) earlier, which was e-mailed to them a few days before the interview took place. They were given prior notice that the interviews could be recorded and could be stopped at any time on request. They were also informed that they could withdraw themselves and any data that they have contributed to the research if they choose so. Participants were given the opportunity to choose the location, day and time of their interview to ensure some degree of confidentiality since the topics are work-related.

The motivation for asking the following questions on publishing practices was to establish whether ECRs are guided about ethics such as in journal selection and authorship practices or correctly adhering to stringent publication ethics, when establishing a strong publication record.

a) What influence (if any) have you had on the choice of journal where your research is published?

b) What drives their choice of journal, especially, to what extent does the quality of a journal influence the decision of whether or not to publish in Open Access journals?

c) What are your views of mega-journals? Would you publish in them?

d) What contributions have you made to the papers that you have co-authored?

e) Via what channels do you share your ideas, research findings, data and publications? Would a more formalised automated system for sharing be helpful? If so, should publishers be involved?

f) Is there a risk of losing competitive edge through sharing and collaborating?

Four questions related to knowledge on unethical behaviours were posed to the participants:

a) For you what is unethical behaviour in scholarly communication?

b) Are you aware of any research misconduct, such as fraudulent/fabricated data or alteration of images in your field? If possible, please supply examples.

c) Are you aware of any publishing misconduct including plagiarism, author identity theft or unethical citing behaviour in your field? If possible, please supply examples.

d) Do you believe there is more scrutiny today which will keep the lid on any unethical behaviours?

The interviews in Year 1 were conducted face-to face at least once with each participant. Interviews lasted between 1 to 2 hours and were conducted in the English language; however, responses were obtained in English as well as Malay language. In year 2, two participants were interviewed through Skype (located in the UAE and UK), while another 
ten face-to-face. Six face-to-face participants were interviewed twice, because the interview could not be completed in due time as they had to leave for other prior engagement. All face-to-face interviews were conducted in the participants' office or research laboratory either nearing or during lunch-time $(11.30$ to $2.00 \mathrm{pm})$ or after office hours $(5.00$ to $7.30 \mathrm{p} \mathrm{m}$ ). This time was chosen due to convenience for the participants. Thus time restraints regulated the duration of the interview session. The Skype interview however gave the participants more flexibility with regards to location and times for the interview. Skype interviews were not recorded. The researcher captured verbatim quotes, and took notes during each session. All interview participants gave consent for the sessions were audio-recorded. Subsequently interview data were transcribed accordingly in the interview schedule by a paid transcriber and checked by the researcher.

More specifically, data on research, publication, productivity and impact obtained from participants' web CV and online presence through ResearcherID (Clarivate Analytics), Scopus ORCID and ResearchGate, were discussed, expanded, clarified, confirmed and reflected during the interviews. Accessing to these data and discussing them during the interview is time-consuming but in this fashion, the participants typically reveal beliefs and attitudes toward the issues at hand.

Since the data collected are qualitative and longitudinal, the first researcher ${ }^{1}$ had to adopt a reflexive stance and be very well-prepared with not only the questions posed, but also with the findings obtained from the first year, so that she would be able to spontaneously reflect on the changes in the participants' scholarly communication behaviour, as well academic and research well-being. The challenge is that, being a prolific author and a university administrator, the first researcher also had to "identify her positionality" (SavinBaden and Howell Major 2013) and her scholarly communication behaviour under scrutiny and be aware how this can only influence the participants' responses and the data collected. These reflections were included during the interview sessions to ensure reflexivity that requires explicit self-consciousness and self-assessment by the researcher about her own views and positions and how these might have influenced the interpretation of the research findings. The researcher as instrument can be the greatest threat to trustworthiness in qualitative research if considerable time is not spent on preparation of the field [and the] reflexivity of the researcher (Poggenpoel and Myburgh 2003)

Member-checking took place during the research process an at the end of data collection, through face-to-face, telephone calls, WhatsApp text messages and e-mails, providing participants with information that ensures their views have been properly captured. No participants withdrew from the study, which suggests that the topic discussed, method of recruitment and the qualitative longitudinal approach were acceptable to participants, an area which is known to be difficult to conduct research.

\section{Participants Background and Career}

The 12 interview participants comprise seven scientists and five social scientists, from eleven subject specialization ${ }^{2}$. All have PhD qualifications, six graduated from Malaysia and another six abroad. All ECRs are parts of a research group, either through a research centre (international status) or an established research group at the faculty (national and/or university status). ECRs coming from research centres are affiliated to the Higher

\footnotetext{
${ }^{1}$ Conducted the interviews with all 12 participants

${ }^{2}$ Ulrich Classification 2015
} 
Institutions' Centre of Excellence ( $\mathrm{HICOE})^{3}$, which are internationally recognised, meeting global standards and in areas of national importance. Those affiliated to research centres are already in the research track ${ }^{4}$. The rest believe that they would be put in the research track in 3-5 years. Table 1 summarizes the participants' information.

Table 1: Demographics, Background the Credentials of the Twelve ECRs

\begin{tabular}{|c|c|c|c|c|c|c|c|c|}
\hline \multirow[t]{2}{*}{ Code } & \multirow[t]{2}{*}{ Gender } & \multirow[t]{2}{*}{ Age } & \multirow[t]{2}{*}{$\begin{array}{l}\text { Disciplinary } \\
\text { Domain }\end{array}$} & \multirow[t]{2}{*}{ Subject specialization } & \multicolumn{2}{|c|}{$\begin{array}{c}\text { Number of } \\
\text { publications } \\
(2016 \& 2017)^{* *}\end{array}$} & \multirow[t]{2}{*}{ Affiliation } & \multirow[t]{2}{*}{$\begin{array}{c}\text { Overseas } \\
\text { training } \\
\text { (PhD) }\end{array}$} \\
\hline & & & & & WoS* & Scopus & & \\
\hline ECR1 & Female & $\begin{array}{c}35 \text { and } \\
\text { over }\end{array}$ & $\begin{array}{c}\text { Social } \\
\text { science }\end{array}$ & $\begin{array}{c}\text { Library and } \\
\text { information science }\end{array}$ & 6 & 7 & Faculty & No \\
\hline ECR2 & Female & $30-34$ & Science & $\begin{array}{c}\text { Computers and } \\
\text { information systems }\end{array}$ & 7 & 0 & Faculty & No \\
\hline ECR3 & Female & $30-34$ & $\begin{array}{l}\text { Social } \\
\text { science }\end{array}$ & Business \& Economics & 1 & 4 & Faculty & Yes \\
\hline ECR4 & Female & $30-34$ & $\begin{array}{l}\text { Social } \\
\text { science }\end{array}$ & $\begin{array}{l}\text { Behavioral and } \\
\text { cognitive science }\end{array}$ & 2 & 0 & Faculty & Yes \\
\hline ECR5 & Female & 30-34 & Science & Biology \& Agriculture & 7 & 6 & $\begin{array}{c}\text { Research } \\
\text { Centre } \\
\end{array}$ & Yes \\
\hline ECR6 & Female & $30-34$ & Science & Chemistry & 20 & 0 & $\begin{array}{c}\text { Research } \\
\text { Centre } \\
\end{array}$ & No \\
\hline ECR7 & Male & $\begin{array}{c}35 \text { and } \\
\text { over }\end{array}$ & $\begin{array}{l}\text { Social } \\
\text { science }\end{array}$ & $\begin{array}{c}\text { Religion } \\
\text { (Islamic studies) }\end{array}$ & 0 & 4 & Faculty & Yes \\
\hline ECR8 & Male & $\begin{array}{c}35 \text { and } \\
\text { over }\end{array}$ & Science & Physics \& Astronomy & 5 & 0 & $\begin{array}{c}\text { Research } \\
\text { Centre } \\
\end{array}$ & No \\
\hline ECR9 & Male & $30-34$ & Science & $\begin{array}{c}\text { Technology \& } \\
\text { Engineering } \\
\end{array}$ & 36 & 4 & $\begin{array}{c}\text { Research } \\
\text { Centre } \\
\end{array}$ & No \\
\hline ECR10 & Male & $\begin{array}{c}35 \text { and } \\
\text { over }\end{array}$ & Science & $\begin{array}{c}\text { Earth and } \\
\text { Environmental } \\
\text { Sciences }\end{array}$ & 4 & 0 & $\begin{array}{l}\text { Research } \\
\text { Centre }\end{array}$ & Yes \\
\hline ECR11 & Male & $\begin{array}{c}35 \text { and } \\
\text { over }\end{array}$ & $\begin{array}{c}\text { Social } \\
\text { science }\end{array}$ & Education & 0 & 3 & Faculty & Yes \\
\hline ECR12 & Male & $\begin{array}{c}35 \text { and } \\
\text { over }\end{array}$ & Science & $\begin{array}{c}\text { Technology \& } \\
\text { Engineering }\end{array}$ & 5 & 0 & $\begin{array}{l}\text { Research } \\
\text { Centre }\end{array}$ & No \\
\hline
\end{tabular}

*Web of Science; may also be indexed in Scopus

** The number of publications refers to new publications from 2016 to May 2017(not counted accepted papers)

\footnotetext{
${ }^{3}$ HICoEs are supported and facilitated by Ministry of Higher Education so that they will become the focused vehicles that will drive R\&D and innovation agenda particularly in fundamental research, as well as contributing to human capital development. The efforts of identifying and acknowledging the achievement of Centre of Excellence in universities will encourage them to work towards becoming a global leader in their research niche areas (https://www.um.edu.my/research-andcommunity/information-for-researchers/higher-institution-centre-of-excellence-(hicoe)).

${ }^{4}$ Research universities in Malaysia are going for three different academic tracks - conventional, teaching \& learning, and research.
} 


\section{FINDINGS}

Ethics of scholarly publishing is part of the publication process, which ECRs must understand. This research postulates that ECRs manifest their understanding of publishing ethics through where they publish their research. Thus, it is important for the study to explore ECRs publishing practices because these reflect their knowledge about common issues in publication ethics and how they demonstrate ethics during the processes. Therefore, the principle questions asked of ECRs was where do they publish their research and how do they apply their understanding of the ethics in the publication execution process.

\section{On Publishing Practices}

\section{(a) Journal Selection}

In general, ECRs are productive authors and they highly publish in the English language. ECRs are focused on publishing in highly ranked journals and outlets are very prescribed, with many ECRs having to publish in institutional lists of acceptable journals. Publishing in Web of Science (WoS) and Scopus-indexed journals is a priority. The scientists (7 of them) are very productive with producing an average of 7.9 published WoS papers in 2016 and 3.7 papers in 2017; the non-sciences had an average of $2.6 \mathrm{WoS} / S c o p u s$ publications in 2017. Table 1 details the differences in publication number between years.

In particular, the sciences are very motivated to publish in Quartile 1 (Q1) and Quartile 2 (Q2) of the Journal Citation Report (JCR) Quartile. The data implies that the sciences do not have issues in publishing their works in impact-factored journals. In general, the ECRs from the sciences do not have complaints about the requirement that they have to publish in WoS-indexed journals. "Where it is indexed is very important - it is strictly Web of Science! Quality first! (ECR6); "The choice has always been ISI (WoS) journals. I learn to be selective in strategy and it can shape a good research career" (ECR5).

The non-sciences have little choice but to follow the university policy and use a proprietary list for publication. Most have not attempted publishing in $\mathrm{SSCl}$-indexed journals and would be doing so in the near future. The most productive ECR is from the LIS, who has 13 publications in $\mathrm{SSCl}$ and Scopus-indexed journals in the duration of about two years. Females (all 3 ) in the social sciences are more inclined to publish in WoS-indexed journals compared to their male counterparts. They seem to have better writing skills and command of the English Language compared to their male counterparts. None use English language editing services in their first review submission. They would only use so "if a paper has been accepted and the editor / publisher requires them to use the service" (ECR3, ECR5). Another (ECR2) acknowledged that editing services are sought only for "student papers". None said getting publishers' editing services. "Not by publishers. Now you can receive a certificate that say your paper has gone through language editing and share that with the editor" (ECR3). The consistent response from those who were trained abroad at their PhD level is that they have never experienced language editing services for their papers.

ECR6 and ECR9, who are affiliated to the HiCOE have published a good handful of WoSindexed scientific articles compared to the rest. This may imply that there is an interest in communicating scientific results, since international funding affects research productivity and impact. The ECRs have become more proficient at the process over time as remarked. "Journal publishing and I have been friends" (ECR9); and "In fact and I am getting good at it, knowing where to publish, choosing the right journals!" (ECR6). The two newly tenured 
who are now given teaching workloads aspired to "push for higher standards in publications to be promoted" (ECR2) by ensuring to "double the number of my publications, I have been forced to write" in the next couple of years (ECR4). The scientists reported that they have already met their 2017 publication KPI in June, and have papers accepted in the pipeline, and while non-sciences confidently said that they would be achieving their publication KPI for 2017. A non-science ECR however indicated that "becoming a highly productive author / researcher in social sciences is difficult". (ECR11)

Findings comparing the 2106 and 2017 responses on factors considered for journal selection are detailed in Table 2, indicating that the ECRs are more conversant with the various factors to consider based on the number of mentions in 2017. While the importance of publishing in WoS-indexed journals and other criteria reported in 2016 are still there (Table 2), this time around, most (at least 75\%) mentioned selecting journals that have the following criteria:

a) Online presence with time-stamp data (10 responses) - Example verbatim: "I can't wait forever to publish my precious research", "The publication took a longer time that the actual research done".

b) Indexed in at least Scopus (9 responses) - Example verbatim "I have good publishing experience with Scopus journals, tracking citations is easy with Scopus journals".

c) The robustness of the journal's peer review processes (10 responses) - Example verbatim "I don't expect journals to have fast acceptance in one month and take less time for peer-review. Why bother to write for a journal which can accept manuscript in 24 hours? It means no peer review, no impact factor, no readers.

d) Journals that are approved by the Ministry and/or University (12 responses) Example verbatim "You should care about publishing in only approved journals, they don't appear in Bealls' list".

Table 2: Factors to Consider when Choosing a Journal to Publish in 2016 and 2017

\begin{tabular}{l||l|c||c}
\hline \hline & Factors to consider when choosing a journal to publish in & $\mathbf{2 0 1 6}$ & $\mathbf{2 0 1 7}$ \\
\hline \hline 1 & Peer-reviewed journals relevant to my research; & 9 & 10 \\
\hline 2 & Multidisciplinary journals related to my discipline & 6 & 8 \\
\hline 3 & Impact-factored journals (Web of Science) & 5 & 8 \\
\hline 4 & Indexed journals (Scopus) & 5 & 9 \\
\hline 5 & Journals with no page charges or submission fees & 3 & 7 \\
\hline 6 & Journals with online presence; online first (published at article level) & 3 & 10 \\
\hline 7 & Journals approved by the university; Ministry & 3 & 12 \\
\hline 8 & Peer-reviewed journals that take less time for review & 2 & 5 \\
\hline 9 & Open access journals but indexed & 4 & 5 \\
\hline 10 & Having both online and print version & 2 & 2 \\
\hline 11 & Reputable Malaysian journals (not necessary in English language) & 2 & 2 \\
\hline 12 & Reputable editorial board members / reviewers & 2 & 4 \\
\hline 13 & Ease of submission (fully automated; easy to follow) & 2 & 6 \\
\hline 14 & Journals with high-functioning web platforms, with DOI, track citation and altmetrics & 1 & 6 \\
\hline 15 & Journals recommended by colleagues and librarians & 1 & 2 \\
\hline 16 & Reputable journals in my field & 1 & 6 \\
\hline 17 & Q1 and Q2 journals in WoS & 1 & 5 \\
\hline 18 & ESCl indexed journals & -- & 4 \\
\hline \hline
\end{tabular}

The scientists made it clear that they do not publish in Open Access journals or publishers that are listed in Bealls' list, hijacked journals and journals that have misleading metrics 
since they only "go for WoS-indexed journals". "We do not have issues when the lists were removed from the website" (ECR6). One ECR lamented the fact that there have been quite a number of journals that are indexed in Scopus and WoS but listed in Bealls'. "OncoTarget and Aging are WoS, but listed in Bealls, should we be cautious about publishing in these journals?" (ECR8). OA journals are only considered provided if they are indexed in either WoS or Scopus - when probed further none mentioned that the grant funder or their institutions mandating publication in OA journals (Gold OA), or making the journal article Open Access at the article level (Hybrid OA).

A new factor to consider that drives their choice of a journal is that it is indexed in $\mathrm{ESCl}$ (Emerging Science Citation Index), and this was highlighted by the ECRs in the nonsciences. Three non-science ECRs mentioned they would publish in ESCl-indexed journals, which they felt is a mark of quality. One ECR (ECR7) equated ESCl as being indexed in WoS - "More Malaysian journals are indexed by ESCI, it has the credential and reputation like ISI (Web of Science)".

\section{(b) Open Access Publishing and Mega Journals}

Open Access Gold Road publishing in general is thought a good idea and not big deal, although disquiet with high charges making playing field uneven between those that can pay and those that cannot, especially the ECRs. When interviewed in 2017, there were no changes, and it is still the case that ECRs will only publish in OA journals if they are WoSindexed. Even the ECR who is now based in UK is adamant that as "I would be coming back to my university in two years' time and I am sure the criteria remain the same" (ECR9). ECR5 has no issue about publishing in OA journals ("No worries, I have seen many top authors in my field publish in OA journals) as long as "the university support to pay for the article charges". However, in general, there is still concern about article processing charges (APCs) which are seen too high for those who do not have research grants or pay to publish as the university will bear the APC only for journals that are in Q1 and Q2.

The majority of ECRs agree with the preposition that OA publishing advances science and research (8), and the rest (5) feel that OA publishing has the tendency to dilute the quality of publications and lacks quality control (most OA journals in my disciplines are of lesser quality but I believe they would be catching up - ECR7). ECR8 equates OA with predatory in relation to the rise of $O A$ journals, although he acknowledged that publishers dismiss the idea through the publication of successful OA journals in many disciplines. However, he believes that "the future these bad publishing will disappear since people are becoming more aware of predatory journals". ECRs in general are very cautious about predatory journals and publishers (avoid such journals and publishers! - ECR1) and they are "going to significant lengths to avoid the collusion with predatory publishing" (ECR3). There is no question among the ECRs that predatory journals constitute an ethical crisis in scholarly publishing that affects many researchers, young or old.

Only the scientists are familiar with mega journals. Much fewer had published in one. ECRs who have experience publishing in mega-journals such as PLOS ONE (3 ECRs) and Nature's Scientific Reports (4 ECRs) did so for three reasons:

a) The journals are indexed in WoS and in the Q1 or Q2 of the JCR quartile.

b) They have research funding to bear the cost of APCs.

c) They were of the opinion that mega-journals have high acceptance rate

The following verbatim express their views: 
My earlier paper was rejected by a conventional journal in my discipline, and it was accepted by Scientific Reports. (ECR6)

PLOS ONE publishes many articles per year, the publication process is fast, and most important is Q1! (ECR10)

Given that UM supports the cost of publishing in Q1 journals, I will submit to this journal. (ECR6)

As long as these journals are in Tier1!! (ECR9)

This is perhaps of most significance for ECRs, who often perceive that the JCR Quartile which they have published as a key factor in the journal selection process. None of the ECRs mentioned about the quality of their research or the soundness of the peer-review process that drives them to publish in mega OA journals.

Archiving their research works in Green OA (archiving in institutional and/or digital repositories) is a non-priority, all ECRs see this as the job of the librarians or research officers hired by the faculties for this purpose.

\section{(c) Authorship Practices}

ECRs in general understand the practice of assigning responsibility for intellectual works and identified the following 11 aspects of author contribution and role:
a) Wrote articles (first author) (7 mentions)
b) Analysis and interpretation of data (5 mentions)
c) Conception and research design (framework and method) (5 mentions)
d) Provision of study materials (4 mentions)
e) Literature review (4 mentions)
f) Statistical expertise (3 mentions)
g) Drafting of the article (3 mentions)
h) Obtaining of funding ( 2 mentions)
i) Collection and assembly of data (1 mention)
j) Corrections and language (1)
k) Critically revise for more intellectual content (1)

The majority of the ECRs (11) know about authorship policy and they highlighted the need to acknowledge funding agencies in their publications. ECRs attest that only those who qualify for authorship are designated as authors in their papers. They noted the policy about giving credit for intellectual work in the form of: Reprint author (9); Description of roles and contribution of authors (6); Sequence of authors (3) and Authors contribution (2). Only one ECR felt that she would do things differently regarding authorship within the research team, pointing out the following:

(a) The bulk of contribution in writing defines the sequence of the authors;

(b) Student would be the first author in the publication pertaining to their research works;

(c) An author would be the corresponding author only if she owns the research and she assumes the overall responsibility in writing the paper ${ }^{5}$

Interviews in 2017 showed that ECRs are more thoughtful and certain about who should be included in the authorship statement; emphasizing that order of authorship should be a joint decision of the co-authors. Deciding who the corresponding author is still an issue

\footnotetext{
${ }^{5}$ In some Malaysian universities, the research supervisor assumes the role of reprint / corresponding author for the publications resulted from their students' theses and dissertations
} 
(being corresponding author has more weight in promotion) and they are happy that some journals allow more than one corresponding author. All indicated that so far they have not experienced authorship dispute regarding publications that they lead. They made it clear that they "do not put those names who have no part in the writing", "omit names of people who do not take part", and "decide the ordering (of authors) that indicates a greater level or participation in the research than is warranted". However, they cannot do much about gift and guest authorship, if the publication is a result of a funded research of which they are not the principal investigator. The sciences thought that it is a good practice for journals that have made authorship description/acknowledgement a requirement when a paper is being sent for review.

\section{(d) Reproducibility of research}

There have been concerns recently that research in science is not as reproducible as it should be (Baker 2016; Peng 2015). Therefore, in the 2017 study ECRs were asked if they were aware of the problem and had any suggestions to make their research more reproducible. The vast majority of ECRs seem to have thought about the problem (9). Only the scientists (7) and 2 non-science ECRs reported having tried to reproduce an experiment, either someone else's or their own. "The efforts and time taken to do the whole research again actually double up"; "we do only for unexpected results". However, none have ever tried to publish a replication study.

When asked if they have any ideas about ways in which the results described in their publications might be made easier for other researchers to reproduce, the ideas suggested are as follows, categorized under 4 themes:

a) Empirical reproducibility (5 responses) -Detailed description/method of the experiment; expose the research workflow; check all steps to trace the raw data aligned with the results; Instrument and protocols are included as appendices; provide supplementary materials like questionnaire.

b) Computational reproducibility (1 response) - Provide readers the codes and data, software, hardware, implementation details, share them online, on blogs or publish together with the paper.

c) Statistical reproducibility (2 responses) - Detailed information on the choice of analysis, statistics, categories and themes; data-sharing, authors should be transparent to report the data and the tests used.

d) Article reproducibility (3 responses): Journals enforcing standards in the way the study is presented; Must have research objectives and questions, theoretical framework, detailed method of the study, clear language that is easy to follow too can someone to replicate a paper.

\section{On Publishing Ethics}

\section{(a) Knowledge of unethical behaviours}

ECRs in this study do not have any formal training in publication ethics. As active researchers, they assume that they already have this knowledge or learn it on the job from their research supervisors, superiors and/or mentors. When interviewed in 2016 all ECRs seemed to have a clear understanding of what is generally regarded as ethical and unethical in research and/or publishing practices, and identified 10 types of unethical practices (Table 4). All of them are personally aware of any unethical publishing/citing behaviour among their peers or among those higher in academic structure, as people have been gossiping about them. However, in 2017, ECRs have a lot to say about this, most probably due to the rising frequency of retractions of Malaysian papers on Retraction Watch (http://retractionwatch.com/category/by-country/malaysia/) that has elicited 
concern of the Malaysian scientific community following wide-ranging postings on social media that questioned the integrity of the researchers.

"It is happening here, people are doing it, unspoken at meetings, but people are talking about it" (ECR1).

"There is no way for me to do things unethical like that, I keep reminding myself not to do the same thing. From where I study, things like this never cropped up" (ECR4).

Fake peer review has been frequently cited as unethical behaviour in 2017. They talked about the consequences of unethical behaviours in publication - especially article retraction and withdrawal. The scientists follow RetractionWatch (http://retractionwatch.com/). "Scientists must tune in to this blog for issues on publication malpractices", said ECR12. Table 4 compares the behaviours identified as unethical publication practices by the ECRs, mentioned in both 2016 and 2017.

Table 4: The Publication Violations Identified by ECRs in 2016 and 2017

\begin{tabular}{|c|c|c|c|}
\hline & Unethical practices & 2016 & 2017 \\
\hline 1 & Plagiarism & 12 & 12 \\
\hline 2 & Salami publishing & 4 & 8 \\
\hline 3 & Duplicate publication / Self plagiarism & 9 & 10 \\
\hline 4 & Excessive self-citation (journal, author, institution) & 8 & 9 \\
\hline 5 & Simultaneous submission & 5 & 6 \\
\hline 6 & Scientific misconduct Fabrication /falsification of data & 4 & 5 \\
\hline 7 & Authorship irregularities (pressured or gift authorship) & 2 & 5 \\
\hline 8 & $\begin{array}{l}\text { Publication for a fee - someone arrange to write a paper for a you and then } \\
\text { get it published in a reputable journal }\end{array}$ & 1 & 5 \\
\hline 9 & Journal editors collaborate with article broker & 1 & 3 \\
\hline 10 & Paper mill & 2 & 6 \\
\hline 11 & Fake peer review & - & 9 \\
\hline
\end{tabular}

An ECR shared a story on citation gaming: "A colleague told me that his paper has been accepted by a journal, and he found out... he complained to the editorial manager that his final author proofs contained six references that he did not cite in the final submission. He suspected the manager informed the editor handling his paper and then he found the references were removed [in the final publication]. The six in-text citations referred to earlier papers authored by the editor handling the paper" (ECR5).

All said that they are completely against any unethical practices. "We owe the truth about our publication, if we cheat because the university's reputations can be affected by what we do" (ECR6). Now all ECRs believe that there is greater public scrutiny and accountability today, which will keep the lid on any publication misconduct. Although their institutions have not taken action (notification of employer) on publication misconduct, ECRs believe that there are attempts, but based on individual and not cohesive effort. They remarked that the punishment ultimately will be in the form of retraction, copyright infringement, mistrust among colleagues, publication ban, and affected reputation.

"Even if the university does not penalize the offenders, the paper retraction is already a punishment if you break the ethical rules". (ECR9)

"Editors are now good at detecting publication fraud; the publishers will ban authors from publication in the journal for a few years and informing the authors and editors of related journals for further action". (ECR7)

"Other people will complain about you, your paper got retracted and the next day you would be on RetractionWatch". (ECR12) 
"People will do a literature search for related papers by the author who misconduct" (ECR1).

ECRs also highlighted that editors and reviewers must have ethical responsibilities - these were highlighted during the interviews - that editors should:

a) Maintain confidentiality

b) Not misappropriate ideas or text

c) Emit reviews that are justifiable and without bias

d) Transmit information to authors in a timely fashion

e) Declare any conflict of interest

An ECR shared this story: "In order for one to publish in this $X$ [she named the journal] journal, your paper must cite a paper in journal $X$. We were told about this, to increase the quartile of the journal, they are using us the soldiers to do this, since they cannot touch the seniors. (ECR4)

\section{Ethics in Publication Sharing}

The ECRs in this study seem to be familiar with academic social network although they do not actively share their publications (and research data) there. All ECRs believe that there is no risk of losing their competitive edge through sharing and collaborating extensively; they see sharing as central to the progress. ECRs almost always want to share - that is their ethical position. Two ECRs remarked using ResearchGate when asked on the platform used for sharing: "ResearchGate! I mainly use it to share ideas, papers and collaborate" (ECR10). "Preprint sharing in ResearchGate is significant enough for authors to take seriously" (ECR1).

One ECR highlighted the issue where data-sharing accompanying a publication might impede authors to submit to a journal that requires so. "Some journals ask us to upload the instrument, additional data, some make this an option, we don't want to submit to journals that complicate the process unnecessarily" (ECR4). In general, there are a number of factors prevent the ECRs for doing so. For example:

a) they want to hold the information so that they can publish articles based on it;

b) the data (especially in science) is confidential as it relates to humans and is difficult to make anonymous;

c) the data is not usable by anyone else because of the way it has been collected.

ECRs are even more conflicted because they now recognise that promiscuous sharing will interfere with their ability to use their results to write exciting new papers, but it does not undermine their basic position. Most of the information obtained from the interviews concerned the sharing of data. The ethics of sharing papers did not come up very often. However, a few did and provided knowledgeable responses, for instance they said:

I understand and respect the policies. Sharing of ideas as a researcher is never discouraged. On data-sharing, authors should be transparent to report the data and the tests used (ECR6).

I believe in open sharing, sharing in ResearchGate and Academia.edu is a practical and effective means to address immediate information needs, and increase opportunities for professional support and networking, discussion of data, and ultimately publishing. We can find international collaborators (ECR1).

In general Malaysian ECRs want more guidance from publishers on what represents safe sharing. When probed if publishers should be involved in a more formalised automated 
system for sharing, those who answered Yes (8) responded as follows, and all seem to be related to copyrights and sustainability:

(a) Publishers can help authors to share responsibly, which version to share (ECR3)

(b) Yes, I have seen this on Elsevier journals, Share links, the journals allow us to share the link for certain period (ECR4).

(c) What some journals are doing now is good, give temporary access to our article, this help us to publicize our work, at least we can share through e-mails the temporary link (ECR6)

(d) They (Publishers) know the appropriate version to share (ECR2)

(e) Why not? Elsevier is doing it, perhaps they can make it more formalised for sharing on ResearchGate (ECR9).

(f) Yes, especially on which authorized copies to share and where (ECR10)

(g) Publishers don't pay us to write, they don't pay the reviewers as well. At least they facilitate sharing of our works, and yes, I would say they should be involved (ECR5).

(h) Our library can't afford to buy journals and put a stop to important databases. Publishers can be more sympathetic in sharing and this helps to make this scholarly (communication) environment sustainable (ECR1)

\section{DISCUSSION AND CONCLUSION}

This paper has provided valuable insights into the ways in which ECRs publish their research and the ethics attached to it. It suggests that ECRs' manifestation of publishing ethics is gauged through their publishing practices, and they are unlikely to misbehave if they have a good understanding and application of the scholarly communication practice/process. ECRs in this study understand that where they choose to publish will affect their career advancement and professional reputation for years to come. The understanding of the issues is much better in the second year of the interview, however much remains the same but there appear to be trends forming and a number of minor, possibly, significant issues occurring.

The challenges faced by Malaysian ECRs are not dissimilar to those experienced by ECRs in other Asian countries, for example in China (Xu et al. 2018). ECRs are faced with the universal academic challenges of publishing and struggling to gain standing or recognition in their discipline. It also illustrates the way in which intellectual contribution can be overridden by considerations of power and performance in academic life (Macfarlane 2015). For the twelve ECRs we interviewed, we found that they give priority to citationindexed journals or those approved by their institution. Moreover, most of them are developing more precise publishing goals and strategies as they continue their careers. Specifically, the findings of this research also show that the ECRs from the sciences publish more in quantity and they are more comfortable in publishing in impact-factored journals. This is closely related to how publication and citation behaviour significantly differ across disciplines (Dorta-Gonzales and Dorta-Gonzales 2013). In particular, Harzing and Alakangas (2016) even claimed that academics in the sciences out-perform their counterparts from the social sciences and humanities in terms of general WoS search citations.

The sciences often perceive that the JCR Quartile, based on where they have published, is a key factor in the journal selection process. It does seem there is a little battle between publishing in OA journals under ethical publishers and pursuing visibility (reputation). None of the ECRs mentioned about the quality of their research or the soundness of the peerreview process that drives them to publish in mega OA journals. This finding is contrary to 
how Davis (2009) illustrated the debate between advocates of OA and OA opponent wherein arguments of transparency and accountability, as well as quality and sustainability of scientific publishing, have deepened the debate about openness and moral publishing practices. Although in the case of Malaysian ECRs, this debate was not apparent. The effort to publish, in any journal perceived as having impact factor, is given more consideration. This could be attributed to the globalisation of higher education through publication (Tan and Goh 2014) and the pressures to publish in the academia (Keen 2007). Moreover, the findings of this study relate to how ECRs become less doubtful of OA journals at present (Nicholas et al. 2017b).

Issues around authorship can be complex and sensitive. ECRs in general understand the norms and practices surrounding research integrity that contribute to authorship assignment and order. However, this study confirms the results of previous studies that there are low levels of understanding as to what constitutes a legitimate claim to authorship (Erlen et al. 1997) since those who contribute statistical expertise, funding and involve in data collection as well as corrections and language are also assigned responsibility for intellectual works. These practices misrepresent authorial credit and can have a particularly significant impact on the development of ECRs. This highlights the need for ECRs to be better informed about their roles and responsibilities for intellectual works in regard to who should and should not be listed as an author and how to order them. This also calls for university policy and training programmes to pay more attention to equity issues connected with authorship. ECRs need to be better informed about the consequences of gift and power ordering of academic contributions to co-authored works and how the Matthew effect (Merton 1973) can "retard rather than accelerate their scholarly recognition when publishing with more renowned senior academics" (MacFarlane 2015 1209).

We observed noteworthy changes in ECRs' attitudes and behaviours regarding publishing and sharing. As compared with data from 2016, the ECRs are more verbose in their responses on what is generally regarded as ethical and unethical in research and/or publishing practices. Authorship policies, the academic evaluation system, and the scrutiny which will keep the lid on any unethical behaviours are the most important factors bringing about the changes we observed. This finding is supported by Abrizah et al. (2014) by presenting that authors assess journals that they read, cite and publish in based on novelty, relevance, characteristics of authors who wrote articles in the journal, presence and quality peer-reviewed, having credible reference lists, published by reputable journals, and having online presence are fit for scholarly utilisation. Hence, the ECRs in this research are still aware of their roles as academics and their ethical responsibilities as researchers.

We have identified in this paper that ECRs enter the world of scientific publishing without much guidance about ethics in publishing; however, they have become more experienced, mature and informed on publication ethics and integrity issues because of their publishing experiences. Inexperienced ECRs or those in less mature universities may be more likely to fall prey to predatory journals and publishers. However, the ECRs in this study were aware of the unethical publication practices in the academe (e.g., such as salami slicing, superfluous writing, plagiarism, repetitious writing, and falsifying), which was also mentioned by Özcan and Balcı (2016). The good thing about the ECRs in this research is the fact that they seem to be learning more about them because of greater exposure to them through social media and publishers' programmes and tools to help ECRs to publish and advance science through good ethical standards. Crystal-clear, specific guidelines about publishing ethics would be a welcome addition to the training of the majority of graduate 
students whom many would become ECRs, and, if effective, would minimize a lot of mental anguish and wasted time. While the issue has been raised and responded to by some organizations such as the Committee on Publication Ethics (Rees 2011), specific guidelines for specific institutions are to be considered. For example, guidelines on authorship are still largely based on institutional policies than a universal one, which also creates differences in the practice of ghost and guest authorship in various institutions and among researchers across disciplines (Ngai et al. 2005; Lissoni and Montobbio 2015; Wislar et al. 2011; Kennedy et al. 2014; Quan 2008; Teixeira da Silva and Dobránszki 2016).

A final finding of interest is that Malaysian ECRs want the availability for their papers to be read by everyone, and they believed that the publishers have a big role to play to facilitate ethical sharing of the publications. The awareness of Malaysian ECRs in this study shows a slight contrast to the findings of Özcan and Balcı (2016) as they saw that half of their ECR respondents had not been informed about the laws and regulations of research ethics or the function of ethics committees in their institutions. This shows that it is not only the publishers who are to ensure the adherence of ethical standards but it must also start in the authors' respective institutions. For journals, a quality and transparent editorial policies and peer-review process also help in making ECRs more aware of their publication practices (Fanelli 2013; Ferris and Winker 2017).

The work reported here limitations that should be acknowledged. It is based on a relatively small sample of ECRs and might not be representative of the Malaysian ECR population at large. It is also based on participants' personal interpretation of the questions and willingness to be reported honestly and objectively. However, as the goal is depth, richness and credibility, instead of representativeness, the small sample size is compensated for by asking in-depth questions and data collection and analysis that has enabled the researchers to extricate a topic that requires a more nuanced investigation than is traditionally undertaken. Therefore, continuing this research with a larger sample, and considering differences among the sciences and non-sciences would shed further light on the publication ethics among ECRs. Further research is needed in exploring whether gift and power ordering practices in academic contribution represent a shift in the publishing behaviour of ECRs over time or remain an essentially unchanged feature of academic life.

\section{ACKNOWLEDGEMENT}

The research reported here has been funded by the University of Malaya Project No BKS079-2017. It was conducted as part of the Harbingers project, which was funded by the Publishing Research Consortium (http://publishingresearchconsortium.com/). All interviewees have provided informed consent to participate in the study and had the opportunity to review the data that were obtained from them. Guarantees of privacy, security, and anonymisation were given to them.

\section{REFERENCES}

Abrizah, A. 2016. Early career researchers: the harbingers of change? An international, longitudinal study of 'changing' attitudes and behaviours in scholarly communication. Country Report - Malaysia. University of Malaya. 72p. 
Abrizah, A. 2017. Early career researchers: the harbingers of change? Year 2. An international, longitudinal study of 'changing' attitudes and behaviours in scholarly communication. Country Report - Malaysia. University of Malaya. 29p.

Abrizah, A. 2018. Publishing your precious research: The ethics of where and how. Paper presented at the Symposium on Malaysian Scholarly Communication. "Going Visible Without Boundaries". 6th February 2018, Ministry of Higher Education, Putrajaya, Malaysia.

Abrizah, A., Badawi, F., Zoohorian-Fooladi, N., Nicholas, D., Jamali, H.R. and Kassim, N.A. 2015. Trust and authority in the periphery of world scholarly communication: A Malaysian focus group study. Malaysian Journal of Library \& Information Science, Vol.20, no.2: 67-83.

Anderson, M.S., Horn, A.S., Risbey, K.R., Ronning, E.A., De Vries, R. and Martinson, B.C. 2007. What do mentoring and training in the responsible conduct of research have to do with scientists' misbehavior? Findings from a national survey of $\mathrm{NIH}$-funded scientists. Academic Medicine, Vol. 82, no.9: 853-860. Available at: doi: 10.1097/ACM.0b013e31812f764c PMID: 17726390. 14.

Baker, M. 2016. 1,500 scientists lift the lid on reproducibility. Nature, Vol. 533, no. 7604: 452-454. Available at: doi:10.1038/533452a.

Berger, M. 2017. Everything you ever wanted to know about predatory publishing but were afraid to ask. ACRL 2017. At The Helm: Leading Transformation March 22-25, 2017. Baltimore, Maryland. 206-217.

CIBER Research Ltd. 2016. Early career researchers: the harbingers of change? Literature Review. Harbingers Working Report 1. CIBER, August 2016. Available at: http://ciberresearch.eu/download/20160901-Harbingers-ECRs_literature_review.pdf.

Davis, P.M. 2009. How the media frames "open access. The Journal of Electronic Publishing, Vol. 12, no.1. Available at: http://dx.doi.org/10.3998/3336451.0012.101.

Dorta-Gonzalez, P. and Dorta-Gonzalez, M.I. 2013. Comparing journals from different fields of Science and social science through a JCR subject categories normalized impact factor. Scientometrics, Vol. 95, no.2: 645-672. Available at: DOI: 10.1007/s11192-0120929-9.

Edwards, M.A. and Roy, S. 2017. Academic research in the 21st century: Maintaining scientific integrity in a climate of perverse incentives and hypercompetition. Environmental Engineering Science., Vol.34, no. 1: 51-61.

Erlen, J.A., Siminoff, L.A., Sereika, S.M. and Sutton, L.B. 1997. Multiple authorship: Issues and recommendations. Journal of Professional Nursing, Vol.13, no. 4:262-270. Available at: doi: 10.1016/S8755-7223(97)80097-X.

Fanelli, D. 2013. Why growing retractions are (mostly) a good sign. PLoS Medicine, Vol.10, no.12:e1001563. Available at: doi: 10.1371/journal.pmed.1001563.

Fanelli, D., Costas, R. and Larivière, V. 2015 Misconduct policies, academic culture and career stage, not gender or pressures to publish, affect scientific integrity. PLOS ONE, Vol.10, no.6: e0127556. Available at: doi:10.1371/journal.pone.0127556.

Ferris, L.E. and Winker, M.A. 2017. Ethical issues in publishing in predatory journals. Biochemia Medica, Vol.27, no.2: 279-84. Available at: https://doi.org/10.11613/BM.2017.030.

Fransman, J. 2014. Becoming academic in the digital age: Negotiations of identity in the daily practices of early career researchers. SRHE Newer Researchers Prize - Final Report. Available at: https://www.srhe.ac.uk/downloads/ FRANSMAN_Final_Report.pdf.

Friesenhahn, I. and Beaudry, C. 2014. The global state of young scientists. Project Report and Recommendations. Berlin (Global Young Academy). Berlin: Akademie Verlag. 
Available at: https://globalyoungacademy.net/wp-content/uploads/2015/06/ GYA_GloSYS-report_webversion.pdf.

Harzing, A.W. and Alakangas, S. 2016. Google Scholar, Scopus and the Web of Science: A longitudinal and cross-disciplinary comparison. Scientometrics, vol. 106, no. 2: 787804. Available at: https://doi.org/10.1007/s11192-015-1798-9.

Keen, A. 2007. Writing for publication: pressures, barriers and support strategies. Nurse Education Today, Vol.27: 382-388.

Kennedy, M.S., Barnsteiner, J., and Daly, J. 2014. Honorary and ghost authorship in nursing publications. Journal of Nursing Scholarship, Vol.46, no.6: 416-422. Available at: doi: 10.1111/jnu.12093.

Kıraç, F.S. 2016. An aspect to the publication ethics subject in the open access online journals. Anatolian Journal of Cardiology, Vol.16: 448-9. Available at: DOI:10.14744/AnatolJCardiol.2016.7293.

Lacetera, N. and Zirulia, L. 2011. The economics of scientific misconduct. Journal of Law, Economics, and Organization. Vol.27, no.3:568-603. Available at: doi: 10.1093/jleo/ewp031.

Lissoni, F. and Montobbio, F. 2014. Guest authors or ghost inventors? Inventorship and authorship attribution in academic science. Evaluation Review, Vol.39, no. 1: 19-45. Retrieved from https://doi.org/10.1177/0193841X13517234.

Macfarlane, B. 2015. The ethics of multiple authorship: power, performativity and the gift economy, Studies in Higher Education, Vol. 42, no.7: 1194-1210. Available at: DOI: 10.1080/03075079.2015.1085009.

Marcella, R., Lockerbie, H., Bloice, L., Hood, C., and Barton, F. 2017. The effects of the research excellence framework research impact agenda on early-and mid-career researchers in library and information science. Journal of Information Science, Vol. 44, no.5:608-618. Available at: https://doi.org/10.1177/0165551517724685.

Merton, R. 1973. The Matthew effect in science (originally published in 1968). In The Sociology of Science: Theoretical and Empirical Investigations, (N. W. Storer, ed), 43959. Chicago: University of Chicago Press.

Mitcheson, H., Collings, S. and Siebers, R.W. 2011. Authorship issues at a New Zealand academic institution. International Journal of Occupational and Environmental Medicine, Vol.2, no.3: 166-171.

Müller, R. 2012. Collaborating in life science research groups: The question of authorship. Higher Education Policy, Vol.25, no.3, 289-311.

Ngai, S., Gold, J.L., Gill, S.S. and Rochon, P.A. 2006. Haunted manuscripts: Ghost authorship in the medical literature, accountability in research, Vol.12, no.2:103-114. Available at: DOI: $10.1080 / 08989620590957175$.

Nicholas, D., Boukacem-Zeghmouri, C., Rodríguez-Bravo, B., Xu, J., Watkinson, A., Abdullah, A., Herman, E. and Świgon, M. 2017a. Where and how early career researchers find scholarly information. Learned Publishing, Vol.30, no.1: 19-29. Available at: DOI:10.1002/leap.1087.

Nicholas, D., Jamali, H. R., Watkinson, A., Herman, E., Tenopir, C., Volentine, R., Allard, S. and Levine, K. 2015. Do younger researchers assess trustworthiness differently when deciding what to read and cite and where to publish. International Journal of Knowledge Content Development and Technology, Vol.5, no.2: 46-53.

Nicholas, D., Rodríguez-Bravo, B., Watkinson, A., Boukacem-Zeghmouri, C., Herman, E., Xu, J. Abdullah, A. and Świgon, M. 2017b. Early career researchers and their publishing and authorship practices. Learned Publishing, Vol.30, no.3: 205-217. Available at: DOI:10.1002/leap.1102.

Nicholas, D., Watkinson, A., Boukacem-Zeghmouri, C., Rodriguez Bravo, B., Xu, J., Abrizah, A., Świgon, M. and Herman, E. 2017c. Early Career Researchers: scholarly behaviour 
and the prospect of change. Learned Publishing, Vol.30, no.2:157-166. Available at: DOI:10.1002/leap.1098.

Noyori, R. and Richmond, J.P. 2013. Ethical conduct in chemical research and publishing. Adv Synth Catal, Vol. 355: 3-8. Available at: doi:10.1002/adsc.201201128.

Nugent, P.M.S 2013. Publication ethics. PsychologyDictionary.org. Available at https://psychologydictionary.org/publication-ethics/ (accessed June 3, 2018).

Nylenna, M and Simonsen, S. 2006. Scientific misconduct. A new to approach to prevention. The Lancet, Vol.367, no. 9526: 1882-1884. Available at: DOI:https://doi.org/10.1016/S0140-6736(06)68821-1.

Özcan, M., and Balcı, Y. 2016. Academicians' views on research and the ethics of publication. Turkish Journal of Business Ethics, Vol.9, no.1: 103-111.

Peng, R. 2015. The reproducibility crisis in science: A statistical counterattack. Significance, Vol. 12, no. 3: 30-32. Available at: https://doi.org/10.1111/j.1740-9713.2015.00827.x.

Poggenpoel, M. and Myburgh, S. 2003. The researcher as research instrument in educational research: A possible threat to trustworthiness? Education, Vol.124, no.2: 418-421.

Pontika, N. 2015. Open Access: what's in it for me as an early career researcher?. Journal of Science Communication, Vol.14, no.04: 1-12.

Quan, S.F. 2008. Guests and ghosts begone-guest authorship and ghostwriting and the Journal of Clinical Sleep Medicine. Vol.4, no.3:203. Available at: http://jcsm.aasm.org/articles/040301.pdf.

Rees, M. 2011. A short guide to ethical editing for new editors. Committee on Publication Ethics. Available at: https://publicationethics.org/resources/guidelines-new/shortguide-ethical-editing-new-editors.

Roberts, J. 2009. An author's guide to publication ethics: A review of emerging standards in biomedical journals. Headache, Vol.49: 578-589. Available at: doi: 10.1111/j.15264610.2009.01379.x

Rodríguez-Bravo, B., Nicholas, D., Herman, E., Boukacem-Zeghmouri, C., Watkinson, A., Xu, J., Abdullah, A. and Świgoń, M. 2017. Peer review: The experience and views of early career researchers. Learned Publishing, Vol.30, no.4: 269-277. Available at: DOI:10.1002/leap.1111.

Savin-Baden, M. and Howell, M.C. 2013. Qualitative research: the essential guide to theory and practice. Abingon, UK: Routledge.

Schroter, S., Roberts, J., Loder, E., Penzien, D.B., Mahadeo, S. and Houle, T.T. 2018. Biomedical authors' awareness of publication ethics: an international survey. BMJ Open, Vol.8, no. 11. Available at: https://bmjopen.bmj.com/content/8/11/e021282.

Stoilescu, D. and McDougall, D. 2010. Starting to publish academic research as a doctoral student. International Journal of Doctoral Studies, Vol.5: 79-92.

Tan, Y.S., and Goh, S.K. 2014. International students, academic publications and world university rankings: The impact of globalisation and responses of a Malaysian public university. Higher Education, Vol.68, no.4: 489-502. Available at: http://www.jstor.org/stable/43648734.

Teixeira da Silva, J.A. and Dobránszki, J. 2016. Multiple authorship in scientific manuscripts: ethical challenges, ghost and guest/gift authorship, and the cultural/disciplinary perspective. Science and Engineering Ethics, Vol.22, no.5: 14571472. Available at: https://doi.org/10.1007/s11948-015-9716-3.

Tennant, J.P., Waldner, F., Jacques, D.C., Masuzzo, P., Collister, L.B. and Hartgerink, C.H.J. 2016. The academic, economic and societal impacts of open access: An evidence-based review. F1000Res, Vol.5: 632. Available at: https://f1000research.com/articles/5$632 / v 3$. 
Tijdink, J.K., Verbeke, R. and Smulders, Y.M. 2014. Publication pressure and scientific misconduct in medical scientists. Journal of Empirical Research on Human Research Ethics, Vol.9, no.5: 64-71. Available at: DOI: 10.1177/1556264614552421.

Uhm, C.S. 2016. What is research misconducts? publication ethics is as important as research integrity. Applied Microscopy, Vol.46, no.2: 67-70. Available at: DOI: https://doi.org/10.9729/AM.2016.46.2.67.

Walker, R. L., Sykes, L., Hemmelgarn, B. R. and Quan, H. 2010. Authors' opinions on publication in relation to annual performance assessment. BMC Medical Education, Vol.10: 21. Available at: doi: 10.1186/1472-6920-10-21.

Wislar, J.S., Flanagin, A., Fontanarosa, P.B., and DeAngelis, C.D. 2011. Honorary and ghost authorship in high impact biomedical journals: a cross sectional survey. BMJ, Vol. 343: d6128. Available at: https://www.bmj.com/content/bmj/343/bmj.d6128.full.pdf.

Xu, J., Nicholas, D., Zeng, Y., Su, J. and Watkinson, A. 2018. Chinese early-career researchers' scholarly communication attitudes and behaviours: Changes observed in year two of a longitudinal study. Journal of Scholarly Publishing, Vol.22, no.3: 320-344. Available at: doi: 10.3138/jsp.49.3.03.

Yanti Idaya Aspura, M.K., Noorhidawati A. and Abrizah, A. 2018. An analysis of Malaysian retracted papers: Misconduct or mistakes? Scientometrics, Vol. 115, no. 3: 1315-1328. Available at: https://link.springer.com/article/10.1007\%2Fs11192-018-2720-z. 